\title{
STUDI KASUS KEHILANGAN KVARH PELANGGAN TARIF I-2 DENGAN DAYA 16.500 VA DAN 17.600 VA DI PT PLN (PERSERO) AREA SEMARANG
}

\author{
Arni Kartikaningtyas, Eko Ariyanto \\ Program Studi Diploma III Teknik Elektro \\ Fakultas Teknik Universitas Diponegoro
}

\begin{abstract}
Arni Kartikaningtyas, Eko Ariyanto, in this paper explain that In electric power transmission and distribution, volt-ampere reactive (var) is the unit used to measure reactive power into AC electric power system. Reactive power in AC circuits when current and voltage are not in phase. Is a true symbol and Var, var, or VAR, but all three terms are widely used. Var terms proposed by Romanian Constantin Budeanu electrical engineer and was introduced in 1930 by the IEC in Stockholm, which has been adopted as a unit for reactive power. Var can be regarded as both the imaginary part of the apparent power, or the power flowing to the load reactive, where voltages and currents specified in volts and amperes. Two definitions are equivalent. Reactive power into the power unit kVArh is used by passive components beyond resistor which is a power loss or power that is not desirable. This power to a minimum to avoid, or at least minimized, although it will not disappear altogether, by minimizing the power factor. Industrial customers are groups of customers with the use of induction machines used for the induction process that requires a great power to drive the motor and pull out the reactive power usage needs to be taken into account. Customers I 2 is the class of tariffs for industrial purposes being at low voltage with power above $14 \mathrm{kVA}$ to $200 \mathrm{kVA}$.
\end{abstract}

Keywords: VAR, customer Industry.

\section{PENDAHULUAN}

PT. PLN (Persero) merupakan satu-satunya perusahaan listrik di Indonesia. Namun dalam perkembangan zaman PT. PLN (Persero) juga berusaha untuk mengembangkan diri demi meraih World Class Standart, sehingga nantinya PT. PLN (Persero) dapat berkembang menjadi perusahaan berstandar internasional. Dalam perkembangannya, penulis menemukan bahwa PT. PLN (Persero) mengalami kerugian daya yang dijual ke pelanggan, yang disebut dengan susut atau losses. Kerugian ini dapat dilihat dari satuan $\mathrm{KWh}$ yang selanjutnya berhubungan dengan rugi secara rupiah yang berpengaruh pada perusahaan. Selanjutnya dilakukan sebuah usaha untuk meningkatkan pendapatan dengan menekan susut sekecil mungkin.

PT. PLN memiliki tenaga jual berupa KWh dan KVARh. Dalam penggunaannya KWh merupakan energi nyata yang digunakan untuk transaksi PLN dan sebagai daya utama yang dijual oleh PLN, sedangkan KVARh merupakan daya reaktif yang diperhitunngkan dalam billing bulanan pelanggan tarif industri, bisnis 3, sosial, pemerintahan dan T/TM, karena pelanggan menggunakan meter elektronik 3 fasa yang menghitung WBP (Waktu Beban Puncak) dan LWBP (Luar Waktu Beban Puncak).

Di pelanggan masih ada temuan yang menggunakan meter tunggal yang tarifnya ganda, sehingga penghitungan jumlah pemakaian KVArh tidak terhitung, maka dari itu PT. PLN mengalami kerugian dalam pengoperasiannya.

\section{TINJAUAN PUSTAKA}

Penulisan laporan ini menggunakkan referensi dari sebuah Laporan yang masih berhubungan dengan hubung singkat yang sebelumnya sudah ada. Judul dari Laporan tersebut adalah Daya aktif, Reaktif dan Nyata yang ditulis oleh Alto Belly,Asep Dadan H,Candra Agusman dan Budi Lukman pada tahun 2010 sebagai mahasiswa Universitas Indonesia.

Laporan ini berisi tentang pengertian daya dan macam- macam beban beserta perhitungan perbaikan kapasitor dalam pemakaian pelanggan. Perbedaan Laporan tersebut dengan Laporan tugas akhir yang dibuat penulis adalah pada pembahasan permasalahannya, pada Laporan yang penulis ambil sebagai referensi tersebut dijelaskan perhitungan secara perbaikan kapasitor untuk memperbaiki $\cos \varphi$, sedangkan pada laporan tugas akhir ini menghitung pemakaian KVAh pada pelanggan I-2 selama satu bulan dengan perhitungan yang bebeda dengan laporan tersebut.

Selain itu dalam Tugas Akhir yang disusun ini dapat dilihat seberapa keugian PLN akibat daya reaktif yang tidak terhitung pada pelanggan I 2 . Sehingga dapat ditarik kesimpulan dari studi kasus yang dilakukan bahwa perhitungan kerugian PLN tesebut apabila digunakan sebagai tagihan susulan pelanggan akan mengurangi susut komersial dan susut daya yang terjadi. Hasil akhir dari laporan tugas akhir ini adalah rekomendasi melalui penedekatan akar masalahnya.

\section{LANDASANTEORI}

Saat pengukuran suatu besaran, baik besaran listrik maupun non listrik, perlu diketahui hal yang 
menyangkut sifat darialat ukur dan definisi mengenai sistem pengukuran. Maksud dari pengukuran tidak lain adalah untuk mengetahui beberapa harga dari suatu besaran yang akan diukur. Dalam hal ini harga yang diinginkan adalah harga yang benar atau paling tidak mendekati harga yang sebenarnya, yang tentu saja tergantung dari tingkat kepresisian, sensitifitas dan keakuratan dari alat ukur yang dipergunakan.

Tiga dasar yang terkait dengan energi listrik, yaitu proses pembangkitan, transmisi dan distribusi. Di pembangkit listrik energi listrik diproduksi, kemudian untuk pengiriman dari gardu induk satu ke gardu induk lain, disebut transmisi. Sedang untuk sampai ke pelanggan, disebut ditribusi.

Secara umum pengertian poses penyaluran tenaga listrik adalah sebagai berikut : Sistem tenaga listrik adalah sekumpulan pusat-pusat listrik yang diinterkoneksi satu dengan lainnya melalui transmisi atau distribusi untuk memasok ke beban atau dari satu pusat listrik dimana mempunyai beberapa unit generator yang diparalel. Proses penyaluran tenaga listrik melalui beberapa tahap, yaitu dari pembangkit tenaga listrik penghasil energi. listrik, disalurkan ke jaringan transmisi SUTET (Saluran Udara Tegangan Ekstra Tinggi) langsung ke gardu induk. Dari gardu induk tenaga listrik disalurkan ke jaringan distribusi primer SUTM (Saluran Udara Tegangan Menengah) dan melalui gardu distribusi langsung ke jaringan sekunder SUTR (Saluan Udara Tegangan Rendah), tenaga listrik dialirkan ke konsumen. Dengan demikian sistem distribusi tenaga listrik berfungsi membangkikan tenaga listrik kepada konsumen melalui jaringan tegangan rendah (SUTR), sedangkan saluran transmisi berfungsi untuk menyalurkan tenaga listrik bertegangan ekstra tinggi ke pusat-pusat beban dalam daya yang besar.

Karena pusat-pusat listrik berada jauh di luar pusat beban, supaya pasokan tenaga listrik tetap stabil terutama tegangan dan frekuensi, dibutuhkan tegangan tinggi, adapun sistem tegangan di Indonesia adalah :

- Sistem kelistrikan di Jawa

$\begin{array}{ll}500 \mathrm{KV} & : \text { tegangan ekstra tinggi } \\ 150 \mathrm{KV} & \text { : tegangan tinggi } \\ 20 \mathrm{~V} & \text { : tegangan menengah } \\ 220 / 380 \mathrm{~V} & \text { : tegangan rendah }\end{array}$

- Sistem kelistrikan di Sumatera, Kalimantan dan Sulawesi mempergunakan tegangan $150 \mathrm{KV}, 20$ KV, dan 220/380 V.

- Sistem kelistrikan di Ambon, NTT, NTB dan Papua mempergunakan tegangan $20 \mathrm{KV}$ dan 220/380 V (Sarimun,2011: 15)

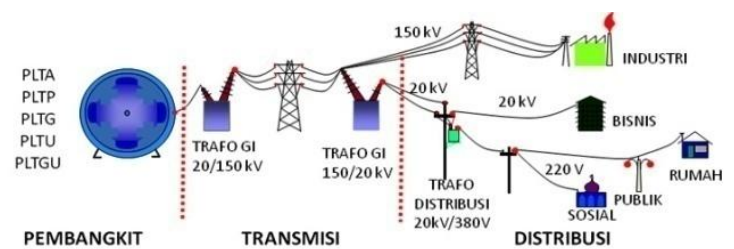

Gambar 1. Alur penyaluran sistem tenaga listrik

Mengingat listrik menjadi kebutuhan utama, maka listrik pun menjadi komoditas bisnis. Komoditas bisnis PT. PLN berupa energi listrik yang dijual ke pelanggan. Satuan energi yang dipergunakan pelanggan meliputi Daya Nyata, Daya Semu dan Daya Reaktif. Untuk mengontrol pemakaian Daya Reaktif ke pelanggan digunakan alat ukur yaitu KVARh meter.

Dengan semakin tingginya tarif listrik, maka tuntutan efisiensi dalam pemakaian daya listrik adalah menjadi pertimbangan utama. Efisiensi penggunaan daya listrik dipengaruhi oleh banyak faktor, di antaranya adalah kualitas daya listrik. Kualitas daya listrik sangat dipengaruhi oleh penggunaan jenis-jenis beban tertentu yang mengakibatkan turunnya efisiensi. Jenis-jenis beban yang mempengaruhi kualitas daya listrik adalah beban-beban induktif, seperti; motor induksi, kumparan, ballast, lampu TL. Demikian juga beban-beban non linier seperti; konverter dan inverter untuk drive motor, mesin las, furnace, komputer, ac, tv, lampu TL dan lain-lain.

Beban-beban induktif akan menurunkan faktor daya, sehingga dapat menyebabkan denda apabila faktor daya kurang dari 0,85 lag, sedangkan beban-beban non linier tersebut menimbulkan harmonisa yang dampaknya akan mempengaruhi kualitas daya, sehingga menimbulkan kerugian kerugian.

Kerugian yang disebabkan oleh harmonisa umumnya berupa :

- Panasnya mesin-mesin listrik karena rugi histerisis dan arus eddy meningkat

- Turunnya torsi motor yang diakibatkan oleh harmonisa urutan negatif

- Kegagalan fungsi relay (kadang-kadang trip sendiri), sehingga mengganggu kontinuitas produksi

- Terjadinya resonansi antara kapasitor bank dan generator/trafo yang

- dapat menyebabkan gangguan-gangguan pada sistem.

- Turunnya efisiensi yang menyebabkan rugi daya.

- Kesalahan pembacaan pada meter-meter listrik konvensional seperti KWh meter (tidak berbasisthrue RMS)

- Panasnya trafo yang dapat menurunkan efiensi maupun bisa menyebabkan terbakarnya trafo.

- Panasnya kabel/kawat netral akibat harmonisa urutan nol, sehingga mengganggu sistem instalasi 
Sedangkan gangguan lain adalah gangguan yang disebabkan karena adanya fluktuasi pemakaian beban, terutama untuk beban-beban yang bersifat on/off seperti crane, furnace, pompa, welding, dll. Gangguan ini dapat mengakibatkan kerusakan-kerusakan antara lain :

- Kerusakan pada sistem instalasi,

- Terganggunya peralatan lain,

- Terputusnya suplai daya,

- Lepas sinkron,

Kerusakan pada prime mover generator, terutama Diesel genset dengan pembebanan sampai $80 \%$, sehingga pada akhirnya akan memperpendek usia pemakaian, seringnya maintenance dan akan memakan biaya pemeliharaan yang cukup besar. Untuk mendapatkan kualitas tenaga listrik yang baik, maka perlu dilakukan langkah-langkah perbaikan kualitas daya (Gomas bogi,2009).

\section{BAHAN PENGAMATAN}

Bahan pengamatan yang diperlukan dalam studi kasus kehilangan KVARh PT. PLN (Pesero) Area Semarang adalah data- data pelanggan yang bertarif I-2 berdaya 16.500 VA dan 17.600 VA, karena pelanggan dengan daya tersebut memang masih menggunakan meter tunggal yang seharusnya menggunakan meter ganda, untuk menghitung penggunaan KWh dan KVARh.

Ada pun yang merupakan bahan dalam pengamatan meliputi : Data Pelanggan catat meter pelanggan I-2 PT. PLN (Persero) Area Semarang. Berikut penulis sajikan data penggunaan KWh dan KVArh pelanggan I-2 dengan daya 16.500 VA dan 17.600 VA se Area Semarang dalam bulan April 2013.

Dalam perhitungan yang penulis sajikan adalah perhitungan penggunaan daya nyata dan daya reaktif, di mana perhitungan penggunaan ratarata nantinya akan dibuat secara rupiah, sehingga akan diketahui berapa besar kerugian energi dan komersil yang dialami oleh PT. PLN (PESERO) Area Semarang selama bulan April 2013.

Pemakaian dalam sebulan dibagi waktu pemakaian dalam sebulan kemudian dibagi daya tersambung untuk mengetahui faktor daya yang ada di pelanggan, kemudian dari hasil tesebut akan diketahi berapa sudut yang diperoleh dan $\sin \varphi$, dan akan diperoleh daya KVARh pada pelanggan tersebuut. Berikut adalah rumus yang diperlukan dalam perhitungan:

$$
\begin{aligned}
& \mathrm{KW}=\frac{K W h}{h} \\
& \mathrm{Cos} \varphi=\mathrm{KW} / \mathrm{KVA} \\
& \Phi=\arccos \varphi \\
& \mathrm{Q}=\mathrm{V} \times \mathrm{I} \times \operatorname{Sin} \varphi \\
& \mathrm{Qt}=\mathrm{Q} \times \mathrm{h}
\end{aligned}
$$

Mencari kelebihan KVARh pada pelanggan I-2 menurut perhitungan PLN adalah sebagai berikut :
- Jumlah KWh LWBP + jumlah KWh WBP = A

- Jumlah KWh LWBP + jumlah WBP x 0,62 = B

- Stand akhirKVARh - stand laluKVARh $\mathrm{x}$ $0,62=\mathrm{C}$

- Jumlah KWh kVARh - jumlah LWBP + jumlah WBP x 0,62=D ( C - B = D )

\section{HASIL STUDI KASUS}

Sesuai dengan hasil studi lapangan yang terjadi, bahwa sesungguhnya kerugian PLN yang disebabkan oleh penggunaan KVARh adalah tidak adanya meter ganda yang terpasang pada pelanggan tarif I-2 dengan daya 16.500 untuk 3 phasa dan 17.600 untuk 1 phasa.

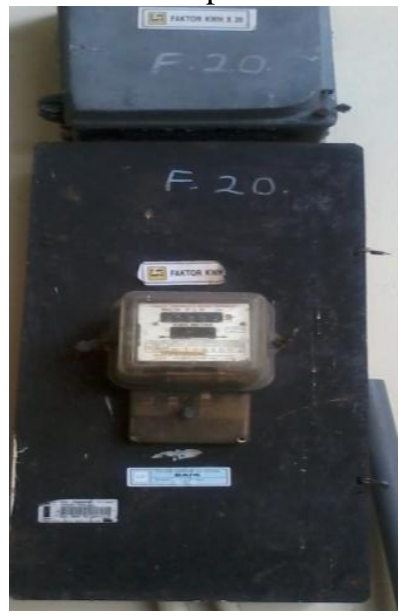

Gambar 2. Meter KWh yang terpasang pada pelanggan I-2 berdaya $17600 \mathrm{VA}$

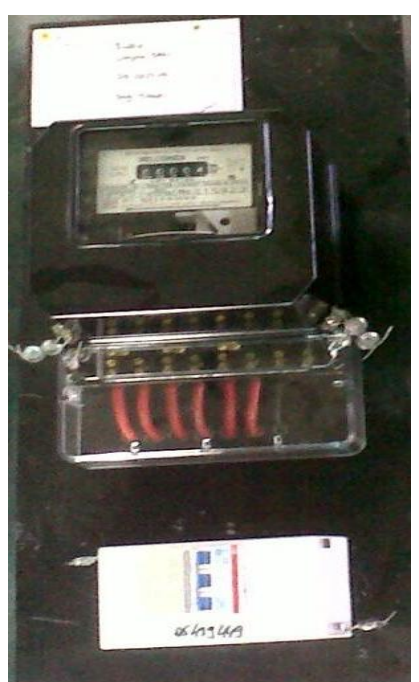

Gambar 3. Meter KWh yang terpasang pada pelanggan I-2 dengan daya $16.500 \mathrm{VA} 3$ phasa.

Hal tesebut merugikan PT. PLN, karena seharusnya dalam perhitungan tarif dasar listrik, pelanggan I-2 dikenakan tarif kelebihan KVARh yang nantinya pada rekening pelanggan akan dijumlahkan dengan penggunaan KWh nya. 
Seharusnya penggunaan meter ganda yang dipasang di pelanggan I-2 adalah seperti pada gambar 4.

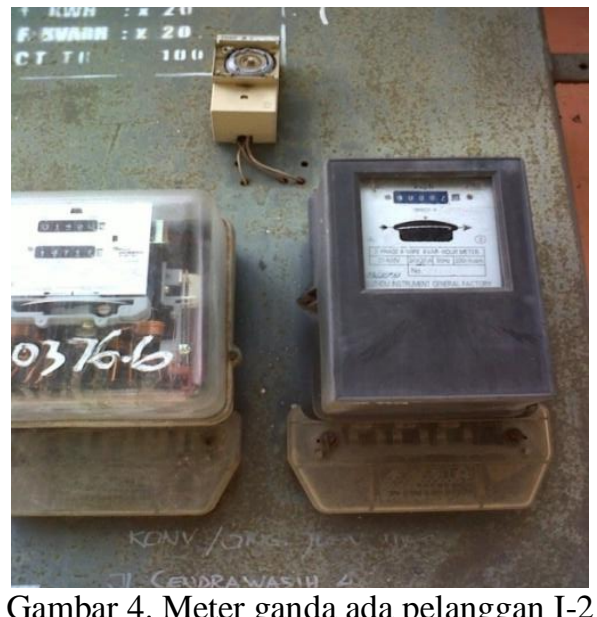

Jadi meter yang terpasang pada pelanggan seharusnya ada 2 meter yang dapat menghitung pemakaian WBP, LWBP dan menghitung KVARh.

\section{PERHITUNGAN}

Penulis menyajikan perhitungan akibat tidak adanya meter KVARh yang menghitung penggunaan daya KVARh pada pelanggan I-2 dengan daya 16.500 dan 17.600 VA. Hal ini diketahui dari data catat meter pelanggan yang ada di data data base PT. PLN (Persero) Area Semarang, yang menunjukan penggunaan KVARh menunjukkan angka nol, karena tidak ada alat untuk menghitung penggunaan KVARh tersebut.

Dalam tabel 3.1 dapat dilihat data pemakaian pelanggan, berikut adalah perhitungan asumsi pemakaian pelanggan yang menggunakan daya lebih dari $1000 \mathrm{KWh}$ dalam satu bulan, karena pada pelanggan dengan pemakaian $\leq 1000 \mathrm{KWh}$ memiliki nilai $\sin \varphi$ yang cukup tinggi. Pada perhitungan kali ini, dibatasi dengan pemakaian $\mathrm{KWh} \leq 1000$ saja yang diperhitungkan, jadi jumlah pelanggan yang menggunakan pemaakaian $\leq 1000$ KWh ada 15 pelanggan. Berikut merupakan perhitungannya:

$$
\begin{aligned}
& \mathrm{S}=17.600 \mathrm{VA} \\
& \mathrm{P} \text { sebulan }=1587 \mathrm{KWh} \\
& \mathrm{H}(\text { Hours })=40 \mathrm{jam} / \mathrm{mi} \\
& \text { /bulan } \\
& \text { (pemakaianefektifpadape } \\
& \text { Perhitungan : } \\
& \mathrm{P}(\text { watt }) \frac{P \text { sebulan }}{H \text { (hours })} \\
& \quad=\frac{1587}{160} \quad=9,9 \mathrm{Kwatt} \\
& \operatorname{Cos} \varphi=\frac{K W}{K V A} \\
& =\frac{9,9}{17,6}=0,5 \\
& \operatorname{Cos} \varphi=0,5 \\
& \Phi=\operatorname{arc~} \cos 0,5 \\
& =55,77
\end{aligned}
$$$$
\mathrm{H}(\text { Hours })=40 \mathrm{jam} / \mathrm{minggu}=160 \mathrm{jam}
$$$$
\text { (pemakaianefektifpadapelangganIndustri) }
$$

$$
\begin{aligned}
\text { Sin } & 55,77=0,82 \\
\mathrm{Q} & =\mathrm{V} \times \mathrm{I} \times \operatorname{Sin} \varphi \\
& =\mathrm{S} \times \operatorname{Sin} \varphi \\
& =17,6 \times 0,82 \\
& =14,43 \mathrm{KVAR} \\
\mathrm{Qt} & =\mathrm{Q} \times \mathrm{h} \\
& =14,43 \times 160 \\
& =2309,2 \mathrm{KVARh}
\end{aligned}
$$

KelebihanKVARh $=\mathrm{Qt}-(\mathrm{P}$ sebulan $\mathrm{x} 0,62$ )

$(1587 \times 0,62)$

$$
\begin{aligned}
& =2309,2- \\
& =1325,18
\end{aligned}
$$

KVARh

Rupiah KVARh = KelebihanKVARh x Rp.914,- / KVARh

$$
\begin{aligned}
& =1325,18 \times 914 \\
& =\text { Rp. } 1.211 .050,-
\end{aligned}
$$

Dengan perhitungan rumus yang sama maka besarnya daya KVARh dan besar rupiah yang merupakan kerugian PLN yang tidak terhitung pada 14 pelanggan yang lain dalam waktu satu bulan ditunjukkan pada tabel 2.

Dalam pehitungan tersebut, ada beberapa yang tidak dicantumkan dari hasil perhitungan KVARh, dikarenakan dalam penggunaan selama satu bulan pelanggan tersebut tidak melebihi 0,62 dari pemakaian $\mathrm{KWh}$, sehingga pelanggan tersebut tidak dikenakan biaya kelebihan penggunaan daya KVARh.

Ada pula pelanggan yang sudah tercantum biaya penggunaan kelebihan KVARhnya, hal ini dikarenakan kenyataan pada pelanggan sudah terpasang meter elektronik 3 phasa yang dapat menghitung penggunaan WBP (Waktu Beban Puncak), LWBP (Luar Waktu Beban Puncak) dan penggunaan KVARhnya.

\section{PENYELESAIAN MASALAH}

Setelah diketahui penyebab terjadinnya tidak terhitungnya KVARh pada pelanggan I2 dengan daya 16500 VA dan 17600 VA, maka dapat diberi saran bahwa penggunaan meter KWh danKVARh yang terpasang seharusnya menggunakan meter elektronik baik berupa meter 1 phasa pada pelanggan 17.600 VA maupun 3 phasa pada pelanggan $16.500 \mathrm{VA}$.

\section{KESIMPULAN}

Kesimpulan yang dapat diambil dari hasil studi lapangan dan perhitungan yang dilakukan mengenai penggunaan daya reaktif pada pelanggan I2 dengan daya $16500 \mathrm{VA}$ dan $17600 \mathrm{VA}$, yang dilaksanakan di PT. PLN (Persero) Area Semarang adalah :

- Kerugian yang dialami PT. PLN (Persero) Area Semarang, disebabkan penggunaan KVArh adalah, tidak adanya meter ganda 
yang terpasang pada pelanggan tarif I2 dengan daya 16.500 VA untuk 3 phasa dan 17.600 VA untuk 1 phasa.

- Selama bulan April 2013 kerugian yang dialami PT. PLN (Persero) Area Semarang untuk pelanggan dengan penggunaan $\leq 1000$ KWh sebesar 22.550,28 KVARh.

- Setelah di rupiahkan, kerugian PT. PLN (Persero) secara komersiil sebesar Rp20.645.002,-

- Pelanggan bernama Jonni Siswanto, Siaw Roy Krisnando dan Budi Raharjo tidak dikenakan biaya kelebihan pemakaian KVARh, karena penggunaan daya KVARh tidak melebihi 0,62 dari total pemakaian KWh dalam satu bulan.

- Pada data base pelanggan I2 daya 16.500 VA dan 17.600 VA ada beberapa pelanggan yang sudah tercantum perhitungan kelebihan KVARh. Hal ini karena pada pelanggan tersebut sudah terpasang meter elektonik 3 phasa.

\section{SARAN}

- Untuk mengatasi losses yang disebabkan tidak terhitungnya daya reaktif, dengan mengganti meter mekanik yang terpasang dengan meter elektronik pada daya 17.600 VA 3 phasa dan 16.500 VA 1 phasa.

- Meter elektronik untuk 1 phasa agar segera di pasang pada pelanggan agar tidak tejadi kerugian yang lebih besar akibat tidak terhitungnya pemakaian KVARh.

- Selama belum ada pemasangan meter elektronik, maka pengukuran KVARh dapat dilakukan secara manual di tempat pelanggan.

- Meter elektronik 1 phasa seharusnya segera dipasang di pelanggan untuk menghindari kerugian yang lebih tinggi.

- Perlu diadakan pengukuran secara langsung untuk menghitung besarnya $\cos \varphi$ yang ada di pelanggan sehingga besarnya angka pasti mengenai kerugian PLN dapatdiketahui.
- Rumus pehitungan tersebut dapat dipertimbangkan sebagai altenatif perhitungan dalam mencari daya KVARh yang tidak tehitung pada pelanggan Industri 2 .

- Pemasangan kapasitor bank dapat memperbaiki nilai $\cos \varphi$ dan dapat memaksimalkan penggunaan tegangan karena fungsi dari pemasangan kapasitor bank selain untuk memperbaiki nilai $\cos \varphi$ adalah untuk menaikkan tegangan.

\section{DAFTAR PUSTAKA}

1. Anonim. 1993, SPLN-94KVARh Meter. Jakarta: PT PLN.

2. Anonim .2013. Volt Ampere Reaktive, (http://en.wikipedia.org/wiki/Voltampere_reactive). Diaksespada 27 Juni 2013.jam 01.02

3. Belly, Alto. 2010. Daya Aktif, Reaktif \& Nyata, Jakarta: Universitas Indonesia

4. Gomas bogi, Angkit Yardewa. Rancang Bangun Kvarh Meter Analog Dan Kvarhmeter Digital Tiga Phasa Sebagai Perbandingan Pengukuran Besaran Listrik. Palembang: Politeknik Negeri Sriwijaya.

5. Harmoyanti B.K, 1981, Rangkaian Listrik, Bandung: Institut Teknologi Bandung.

6. Ramdhani, Mohammad. 2008. Rangkaian Listrik. Jakarta: Erlangga.

7. Sarimun, Wahyudi .2011. Buku Saku Pelayanan Teknik. Depok : Gramond.

8. Tituitcom .2012. Induktor pada rangkaian AC.

(http://accurations.wordpress.com/category/pe ndidikan/page/18/) Diaksespada 27 Juni 2013.jam 11.48

9. UMY. 2013. First Elektronik, (http://blog.umy.ac.id/yssyrhmll/2012/05/23/fi rst-electronics-5/). Diaksespada 27 Juni 2013.jam 11.55

Tabel 1. Pelanggan I2 daya 16500 VA dan 17600 VA Area Semarang bulan April 2013

\begin{tabular}{lllllll}
\hline Unitup & Nama & Tarip & Daya & Pem KWH & KWH KVARH & Kelb KVARH \\
\hline 52301 & Agus Sutjipto Konfek & I2 & 17600 & 1587 & 0 & 0 \\
52301 & Tan Hien Swie & I2 & 17600 & 1000 & 0 & 0 \\
52301 & Siany Melly & I2 & 17600 & 1380 & 0 & 0 \\
52301 & Jono Siswanto Sm & I2 & 17600 & 5828 & 0 & 0 \\
52301 & Siauw Roy Krisnando & I2 & 16500 & 4300 & 0 & 0 \\
52302 & H Dirho Wahono M & I2 & 16500 & 1894 & 0 & 0 \\
52303 & Benny Subrata & I2 & 16500 & 1046 & 0 & 0 \\
52303 & Budi Cahyono & I2 & 16500 & 1122 & 0 & 0 \\
52303 & Pt Dragon Prima F & I2 & 16500 & 1368 & 0 & 0 \\
52303 & Kang Bing / Pbr Mie & I2 & 16500 & 2080 & 0 & 0 \\
52303 & Budi Rahardjo & I2 & 16500 & 2717 & 0 & 0 \\
52303 & Handoyo Andy C & I2 & 16500 & 1760 & 0 & 0 \\
52307 & Bambang Waluyo Ba & I2 & 16500 & 1289 & 0 & 0 \\
\hline
\end{tabular}


Tabel 2. Hasil Pehitungan kerugian dayadan di rupiahkan

\begin{tabular}{|c|c|c|c|c|c|c|c|}
\hline Unitup & Nama & Tarip & Daya & $\begin{array}{c}\text { Pem } \\
\text { KWH }\end{array}$ & $\begin{array}{c}\text { Pem } \\
\text { KVARH }\end{array}$ & $\begin{array}{c}\text { Kelb } \\
\text { KVARH }\end{array}$ & Rupiah \\
\hline 52301 & $\begin{array}{l}\text { Agus Sutjipto } \\
\text { Konfek }\end{array}$ & $\mathrm{I}-2$ & 17600 & 1587 & 0 & 1325,18 & 1.211 .050 \\
\hline 52301 & Tan Hien Swie & $\mathrm{I}-2$ & 17600 & 1000 & 0 & 1999 & 1.827 .086 \\
\hline 52301 & Siany Melly & $\mathrm{I}-2$ & 17600 & 1380 & 0 & 1599 & 1.461 .486 \\
\hline 52301 & Jono Siswanto Sm & $\mathrm{I}-2$ & 17600 & 5828 & 0 & - & - \\
\hline 52301 & $\begin{array}{l}\text { Siauw Roy } \\
\text { Krisnando }\end{array}$ & $\mathrm{I}-2$ & 16500 & 4300 & 0 & - & - \\
\hline 52302 & H Dirho Wahono M & $\mathrm{I}-2$ & 16500 & 1894 & 0 & 1821,6 & 1.664 .942 \\
\hline 52303 & Pt Tanah Makmur & $\mathrm{I}-2$ & 16500 & 1196 & 0 & 2353,5 & 2.151 .142 \\
\hline 52303 & Slamet Purnomo & $\mathrm{I}-2$ & 16500 & 1815 & 0 & 1814 & 1.689 .072 \\
\hline 52303 & Benny Subrata & $\mathrm{I}-2$ & 16500 & 1046 & 0 & 2423 & 2.215 .480 \\
\hline 52303 & Budi Cahyono & $\mathrm{I}-2$ & 16500 & 1122 & 0 & 1122 & 1.025 .508 \\
\hline 52303 & Pt Dragon Prima F & $\mathrm{I}-2$ & 16500 & 1368 & 0 & 2257 & 2.063 .733 \\
\hline 52303 & Kang Bing / Pbr Mie & $\mathrm{I}-2$ & 16500 & 2080 & 0 & 1625 & 1.485 .973 \\
\hline 52303 & Budi Rahardjo & $\mathrm{I}-2$ & 16500 & 2717 & 0 & - & - \\
\hline 52303 & Handoyo Andy C & $\mathrm{I}-2$ & 16500 & 1760 & 0 & 1967 & 1.798 .514 \\
\hline \multirow[t]{2}{*}{52307} & Bambang Waluyo Ba & $\mathrm{I}-2$ & 16500 & 1289 & 0 & 2244 & 2.051 .016 \\
\hline & & & & & Jumlah & $22.550,28$ & 20.645 .002 \\
\hline
\end{tabular}

